\title{
How Ecosystem-Based Adaptation to Climate Change Can Help Coastal Communities through a Participatory Approach
}

\author{
Liette Vasseur (iD)
}

Citation: Vasseur, L. How

UNESCO Chair in Community Sustainability: From Local to Global, Department of Biological Sciences, Brock University, 1812 Sir Isaac Brock Way, St. Catharines, ON L2S 3A1, Canada; lvasseur@brocku.ca; Tel.: +1-905-688-5550 (ext. 4023)

\begin{abstract}
Coastal rural communities worldwide face many challenges not only related to climate change but also extreme events, environmental degradation, population growth or aging, and conflict usage of the ecosystem. Historically, the economies of coastal communities have been based on the exploitation of natural resources, thus shaping its socioeconomic development. This has led to some limitations in the way these communities can now adapt to climate change. In Canada, coastal communities are increasingly dealing with climate change consequences. Sea level rise, coastal erosion, and increasing frequency in storm surges threaten the fragility of both natural and human systems. Various approaches have been used to try to reduce the vulnerability and improve adaptive capacity of communities. One approach, promoted by many organizations including the United Nations, is ecosystem-based adaptation. This approach is part of the series of nature-based solutions that help social-ecological systems become more resilient; by promoting biodiversity conservation and ecosystem services, this approach also relates to principles of community engagement and supports adaptive governance and social inclusion. This paper describes and analyzes these principles and considers strategies for ensuring community engagement. Combining ecosystem-based adaptation with a strong community engagement can enhance the long-term sustainability of the social-ecological system.
\end{abstract}

Keywords: community engagement; community sustainability; nature-based solutions; climate change; adaptation; participatory action research

\section{Introduction}

Coastal communities across the world have traditionally been related to their natural ecosystems. Their economies are largely dependent on the availability of natural resources such as shellfish, fish, or even coastal habitats. Historically, their intricate connection made coastal communities well aware of any changes happening in their environment, whether they were physical or climatic. In the past century, coastal communities have seen many land changes due to an increase in population size and economic activities, resulting in new construction of residences, industries, commercial complexes, and road infrastructures. Overtime, these settlements have become closer and closer to the coastline, resulting in huge pressure on the natural coastal ecosystem that previously had served as a buffer against storms or other extreme weather events coming from the ocean [1]. More recently, awareness of the increasing impacts of climate change, with additional issues such as sea level rise, have raised questions about the sustainability of coastal anthropo-systems that currently do not consider the natural system component.

Climate change has increasingly impacted coastal communities due to an increase in frequency and/or intensity of extreme weather events, such as storm surges and extreme rainfall resulting in flooding, coastal erosion, and infrastructure damage. While these changes vary among regions around the globe, their impacts depend on both vulnerability and exposure of the communities and their natural ecosystems [2]. Sea level rise (SLR) is 
often seen as a major factor, although because of its slow progression people tend to not react to it. SLR varies greatly among regions, depending on topography, oceanic thermal expansion, and continental movements [3]. In Atlantic Canada, for instance, sea level has increased over the past century by $30 \mathrm{~cm}$ and is projected to increase by another 26 to 98 $\mathrm{cm}$ by $2100[4,5]$. As these changes are generally impacting at the local level, it has become clear that solutions must be locally suited to ensure the sustainability of these communities and their natural and managed ecological systems.

Mitigation, which for a long time has been promoted as the unique solution to combat climate change, is essential and more needs to be done as stressed by the United Nations Framework Convention on Climate Change (UNFCCC) and the Paris Agreement, but adaptation is now part of the climate change strategy. Adaptation to climate change has increased as an important subject in the Intergovernmental Panel on Climate Change $[2,6,7]$ reports with the admission that even if greenhouse gas emissions were to be stopped rapidly, impacts on the environment and therefore human livelihood (including mental and physical health) can continue for decades and most changes will be irreversible. Adaptation is a complex topic that has resulted in the development of various concepts and approaches. For a while, adaptation has been mostly examined from a societal response viewpoint, with the belief that human activities need to adapt with little or no consideration for the rest of the natural ecosystem [8]. In the past decade, the importance of the natural ecosystem in climate change adaptation has taken a new dimension, where it is not only a question of ensuring that it can adapt but also the realization that it can be a vehicle for the social-ecological system to adapt [9].

For many other communities that rely on natural resources, the idea of ecosystembased adaptation has increasingly received a lot of interest. Ecosystem-based adaptation can be defined as any strategies or actions that promote the use of nature-based solutions to enhance the sustainability and the resilience of the social-ecological system [10-12]. Ecosystem-based adaptation ( $\mathrm{EbA}$ ) has been promoted by many international organizations, such as the International Union for Conservation of Nature (IUCN), the United Nations Environment Program (UNEP), and the United Nations. The Global Climate Action Summit in 2018 recognized these strategies as essential and was one of the major focuses for the UN Climate Change Summit in the fall of 2019 [13].

In this paper, my aim is to first introduce the concept of $\mathrm{EbA}$, which has been highly relevant for coastal communities and can be used to increase resilience of communities. It is not a systematic literature review as many already exist on $\mathrm{EbA}$ and adaptation. Rather, I aim to bring some of the various considerations and elements that can be important to include in any project to ensure that community engagement is effective for implementation of EbA. I therefore briefly review the various types of adaptation, including EbA. I then explain some of the tools that can enhance community engagement and improve governance and empowerment at the community level. It is important to note that EbA, like many other nature-based solutions, should be grounded in the field, engaging community from the start of any project. I finally underline other considerations from my own experience to ensure that community engagement is meaningful and successful in EbA projects.

\section{Various Approaches to Adaptation}

Responses to climate change have come from various perspectives depending on the discourses promoted by researchers and policy makers at the national, regional, or community level. Adaptation relates to the concepts of vulnerability, resilience, and disaster risk reduction [14]. The aim ultimately brings the idea of ensuring sustainability in communities and as such, adaptation needs to be considered in a broader approach than just from a human perspective [15]. The Intergovernmental Panel on Climate Change (IPCC) introduces the concept of adaptation as "adjustment in natural and human systems in response to actual or expected climatic stimuli or their effects, which moderates harm or exploits beneficial opportunities" [16] (p. 982). This definition has evolved over time but underlines that adaptation can be reactive or proactive, and it includes both natural and 
human components, and reduces impacts. Under a sustainability framework, adaptation encompasses "spatial, temporal, and developmental dimensions" [14] (p. 21) and involves decision-making and policy development as various strategies become available.

There are various types of adaptation strategies. Technological or structural adaptations relate to physical or engineered manipulations or interventions and can include measures such as construction of a protection wall, infrastructure improvement, and even structural relocation [17]. Policy-based adaptation approaches involve defining national strategies, long-term planning, development of emergency measures, and legislation from local to national levels [17]. Most of these adaptations are top-down and left to decision makers. Various sustainable governance policies (such as increased financial and resource support for adaptation mechanisms) can foster partnerships and collaborative networks for climate change resilience at the municipal/local scale [18]. Policy-based and technological adaptation approaches can often be combined. As stated by Hung et al. [19] (p. 3), "Policy-based adaptation frequently combines risk assessments with structural engineering projects to moderate risks and to deploy 'no-regrets' adaptation interventions". Combining policy-based adaptation with technological adaptations, as they are generally top-down decisions, can unfortunately lead to barriers and conflicts with the citizens [19].

To reduce such conflicts, community-based adaptation $(\mathrm{CbA})$ has been promoted as an approach that can be more inclusive at the local level, as it combines the development with adaptation strategies that encourage communities to implement measures [17]. Ayers and Forsyth [20] (p. 26) state that the CbA approach includes "participatory processes, involving local stakeholders and development and disaster risk reduction practitioners". $\mathrm{CbA}$ differs from previous top-down approaches, as it involves local stakeholders and can improve actions at the local level. It is usually promoted and done by non-governmental organizations (NGOs) or other organizations, involving local stakeholders in consultations, surveys, or activities [17]. These community-based/grassroots adaptations take many forms but generally include collective actions initially at a small scale (which can spread across other neighborhoods or communities), triggered by lack of commitments from governments, involving traditional or ecological knowledge and local actors, and addressing the hazards that are the most important for their community [21].

It is important to also emphasize that most of these actions target the community and its social system and can include activities such as a community garden, community emergency system, etc. $\mathrm{CbA}$ also has some challenges, such as governance issues, as most actions are bottom-up and may not be recognized by authorities or integrated into policies [22]. For example, Forino et al. report that, in the case of Hunter Valley in Australia, while community-based initiatives (CBIs) are very positive to enhance adaptation, "formal institutions (e.g., multi-level governments, agencies, and organizations) should be more proactive in working in coordination with these CBIs and providing them with genuine support and engagement, targeted towards local community needs" [21] (p. 64).

For local decision makers and planners in communities, especially small rural communities, finding the best paths to lead to adaptation can be complex. Once they have assessed their vulnerability and they understand the climate change projections, they have to develop adaptation solutions. In this perspective, I do not examine the modeling and vulnerability steps prior to adaptation, which is a review in itself. There are various adaptation pathways or decision-making tools that can help them. In general, these tools categorize climate change adaptation as grey adaptation, which can be considered technological adaptation; soft adaptation where "significant investments in soft infrastructure, namely improving the technical, organizational, and social capacities of administrative and social systems to respond to climate-related stress" [23] (p. 327); green adaptation or here called $\mathrm{EbA}$; and, community-based adaptation. For most communities, adaptation planning remains a challenge, and, as often mentioned, involvement of the local people can help define the options, as many of them can be combined [24]. 


\section{What Is Ecosystem-Based Adaptation?}

In the past decade, the realization that nature can be an ally in defining solutions and strategies to adapt to climate change has led to the development of ecosystem-based adaptation (EbA) strategies. EbA "builds resilience and reduces the vulnerability of local communities to climate change. Through considering the ecosystem services on which people depend to adapt to climate change, EbA integrates sustainable use of biodiversity and ecosystem services in a comprehensible adaptation strategy" [11] (pp. 15-16). This approach is especially attractive for local coastal communities where the economy relies largely on natural resources and therefore on ecosystem services. Ecosystem services are all the benefits provided by humans from nature [25-27]. In the case of climate change, regulating services are critical as they can contribute to climate regulation or erosion prevention. In addition to provisioning (e.g., food and timber) and cultural (e.g., spirituality or recreation) services, supporting services are at the base and relate to ecosystem functions in terms of services such as nutrient cycling, primary production, etc. [27]. The premise of EbA lies on the principle that if an ecosystem is healthy, it is more resilient to any disturbance, and therefore the human component of this ecosystem should be capable to adapt to changes, i.e., more resilient as well [11]. Therefore, EbA goes beyond addressing climate change impacts through adaptation and ecosystem services and biodiversity conservation in the short term, as it reduces the vulnerability of the social-ecological system, improving the sustainability of both people and the ecosystem in the long term [11]. It is worth mentioning that $\mathrm{EbA}$ does not preclude physical or technological solutions when they are necessary, but the first intent should always focus on protecting biodiversity and ecosystem services [13].

To be successful, EbA needs to combine the efforts of society, decision makers at the community level, scientists, and other experts to ensure that adaptation strategies and solutions can be mainstreamed. It links the bottom-up approach of $\mathrm{CbA}$ with the top-down system of policy-based adaptation by allowing a space for dialogue, where biodiversity and ecosystem services can play a greater role to help adapt to climate change $[10,13]$. For example, decision makers can provide innovative types of funding to help support community efforts to restore a salt marsh or to support scientists who are delimitating the width of a buffer zone in a coastal area where erosion is important.

\section{Tools for Connecting People and EbA}

The engagement of the community should be therefore central for the effective implementation of EbA. Here I present some of the methods that have been found effective and have been also used with success in my research. Community-based research and especially participation action research (PAR) are well-suited to implement EbA in a community. PAR is defined as an iterative process of research and actions in the field or in a community that allows for the engagement of various actors with researchers [28]. The aim is to co-define the issues at stake, discuss solution options, analyze them, and make decisions or recommendations that are usually socially, economically, and environmentally acceptable. PAR therefore requires a continuous involvement and exchange among actors, scientists, and decision makers [29] and relates to the pillars of EbA [30]. Activities in PAR can evolve in various ways, depending on the questions or issues expressed by the community during events (workshops, kitchen assemblies, science café, dialogues, etc.). There are several advantages of integrating EbA and PAR. PAR tends to lead to improved awareness through social learning, as questions from actors involved in the process feed the co-production of knowledge [31]. It increases the likelihood of social acceptance of the proposed adaptation measures, as people are involved from the start of the process.

Like PAR, EbA acknowledges that communities are diverse, and each of them will be characterized differently. A good appreciation of the profile of the community includes its levels of education, income, economic activities, services, governance, cultural diversity, and social cohesion and network [28,32]. A profile defining all the aspects of the community helps ensure that no one is missed when it is time to start discussions with the actors of 
the community. This can be done by collecting information that is public or through interviews with the main actors $[29,33]$. Understanding the status of the natural ecosystem provides the basis for EbA action [34]. Activities to ensure that everyone is involved means that various communication and outreach methods are included, such as kitchen assemblies [34], workshops, science cafés, and youth camps. These methods ensure that information is well communicated to increase awareness, improve social learning and trust, and support the co-production of knowledge, and thus co-construct solutions or strategies [19].

The profile can be complemented by a social network analysis. Crona and Parker [35] (p. 4) define social network analysis as a "method to quantitatively measure the number, types, and intensity of social interactions between actors and social groups". Many tools are freely available (e.g., Gephi.org; Cytoscape.org; Network Workbench (http:/ / nwb.cns. iu.edu/) accessed on 20 November 2020) with the capacity to define the linkages among people and the types of relationship they have. For example, Vasseur et al. [32] have used Gephi to understand the dynamics in coastal communities of Quebec and developed a guide to maintain this capacity for other communities through the ResAlliance project (https:/ / robvq.qc.ca/public/documents/bibliotheque/uploaded/i6d20Ctl.pdf, accessed on 14 October 2020). Building partnerships among the various actors in the community, including private and public sectors and local actors, is crucial to an effective approach [10]. $\mathrm{EbA}$ is therefore based on the premises of transparency, inclusion, accountability, trust, and engagement [32,36].

For EbA to be effectively operational at the local level, the governance systems in place should be examined to ensure meaningful engagement of all actors of the community $[33,37]$. The ecosystem governance approach promotes projects and actions that are inclusive, adaptive, and flexible, devolved to the community, and aiming for sustainability, while respecting the limitations of the ecosystem services on which the community relies [38]. The steps to ensure a successful process include activities such as understanding the issues from all points of view, including ecological, physical, social, economic, technical, cultural and health; social learning and dialogue between actors and scientists; and co-construction of solutions of strategies (http:/ / aruc.robvq.qc.ca/ public/documents/bibliotheque/Resilience\%20kit\%20ENGLV\%20nov2012.pdf, accessed on 14 October 2020; [34]).

Moving from community awareness to community engagement can be a major step in any project. Trust between a municipality and its citizens may be the first barrier to moving toward a more active engagement than simple involvement. Wamsler et al. [39] suggest that, from the decision-makers perspectives, citizen involvement may often be limited negatively, hindering the actions that the municipality may try to implement. The major challenge is not only the level of awareness but rather other factors such as trust, perceived transparency in decision-making, and even understanding of the issues. Municipalities tend to be not always well equipped to explain issues and clearly fail to justify why some actions may be suitable to adapt to climate change, especially if they relate to EbA [39].

When trust is built and municipality-citizens relations are such that meaningful engagement is possible, co-production of knowledge and co-construction of solutions or strategies can translate into ensuring adaptation action. This step requires respecting the various cultures and classes of the community and understanding the ecosystem in which the community lives. Using PAR or not, any project needs to be clearly explained to all actors, i.e., all individuals including women, non-binary persons, and men of all ages, from youth to elderly people, so dialogue among them can take place [28,30]. Having such an engagement translates into co-construction of solutions that are more socially acceptable and often more feasible than top-down decisions made by either decision makers of the community or experts who do not live in the community and therefore will not have to deal with the consequences of the decisions [40].

While Wamsler et al. [39] report that from decision makers' perspectives, naturebased solutions to climate change do not always lead to positive outcomes in terms of 
community engagement, the reasons invoked underline the importance of changing the way messages are generally brought up to citizens and the processes used to have them involved. Conflicts and protestations are often related to limited capacity of the system to engage with open dialogue, lack of clear understanding of the issues, and justification for potential actions, etc. Wamsler et al. [41] suggest four strategies to overcome these barriers: institutional support through resources and citizen participation; policy or legal legitimate action to reduce conflicts; financial and human support to increase citizen engagement; and knowledge and capacity building to ensure understanding of the issues.

I agree with these initial strategies as they are at the basis of many challenges faced when a community needs to move forward on climate adaptation. However, other considerations can be put forward here. One of the first considerations is the need of transparency and inclusion of all actors in such an initiative started either by researchers and/or with the participation of decision makers from a municipality. For example, having a public launch of a new project-such as in the case of a project in the Municipality of Greater Sudbury [42] and in the current project of the Town of Lincoln (www.brocku.ca/unesco-chair/meopar, accessed on 22 December 2020) —increases awareness among citizens and their interest to be involved. Maintaining an open communication channel is necessary to bring trust to the communities. In the case of Lincoln, we are currently maintaining weekly blog posts on the website as well as in local newspapers. The posts have two purposes: first, to engage the community and second, to help citizens better understand the terms generally used in climate action but not well explained, except scientifically. This strategy was adopted following interviews that the team did with diverse stakeholders requesting the need for more information using less scientific jargon. Indeed, the main impediment to climate action has been a lack of knowledge and understanding [39,41]. The blogs have already brought attention to residents who are contacting me about their properties for advice. At the same time, it is important to not create expectations and, in some cases, ensure that they are directed to the right and more appropriate experts when needed. Knowledge mobilization, such as these blog posts, encourages a greater exchange of ideas and information among people engaged in a dialogue, as they can make a greater impact on decision making and actions that are taken at the community level. Knowledge must be accessible to all actors and communicated in various formats from meetings to social media [43].

Enhanced community engagement in EbA can lead to unexpected outcomes as it can promote many other activities that link people and nature [44]. For example, once actions are implemented, such as the restoration of a buffer zone along the coast, monitoring and evaluation are essential activities, and they can involve school children or volunteers through citizen science [45]. They are part of ensuring that actions are positive and effective as adaptation measures and essential in ecosystem governance, which is based on an adaptive approach. While monitoring and evaluation are often the poor children in the cycle of adaptation actions, there are many ways to conduct them based on community participation. Citizen science can have positive impacts as people remain involved in the EbA process [44].

Challenges remain with all these approaches that may seem a priori very positive. Skeptical people (usually uninterested in being involved and often adding blogs or comments in media published on a specific event) or people with a specific agenda may try to disrupt the process (during public meetings), limiting the efforts of others. Many tactics are now available to reduce skepticism, including several narratives from various organizations [46].

PAR and $\mathrm{EbA}$, when correctly done, are demanding and time consuming, as unexpected questions or requests may arise, requiring reexamining some aspects of the project. Both rely on an interdisciplinary team, as various disciplines may have to be involved in the discussion and analysis of the various options [47]. Mostly likely, because EbA requires time, many projects previously analyzed by Brink et al. [36] suggest that few have used a participatory process. PAR needs to be carefully planned, and proper ethical considerations must be respected. This is especially important when Indigenous Peoples or 
marginalized groups are involved, and meaningful respectful engagement is critical. This is where traditional knowledge becomes a crucial part of the process and can help co-define strategies. Indigenous Peoples and local communities have a wealth of knowledge that must be respected and integrated as part of the process. The guiding principle of "TwoEye Seeing", developed by Elder Albert Marshall [48], then becomes essential to merge both scientific and traditional knowledge. Caution should also be placed in the possible saturation of the community regarding the number of activities that may be required to advance in co-constructing solutions or strategies [49].

This may be important in small coastal communities where few people are involved due to many other commitments. Volunteer burnout is therefore a real issue and should be considered when planning activities, especially when it is time to implement actions such as community restoration of a buffer zone, for example, or its following monitoring [50]. This is where innovative solutions may be important to define. In Xiamen, China, for example, the reforestation of the mangroves, viewed as essential after they were initially destroyed to build resorts along the coast, which were eventually levelled by a typhoon in 1999, was started with the use of school children who helped plant thousands of small trees [40]. This strategy helped to rapidly move forward with reforestation, as few adults were available to help due to other commitments.

\section{Conclusions}

It is important to remember that through geological time, ecosystems have evolved with a changing climate. This is the foundation of all ecological systems. However, with accelerated change due to anthropogenic activities, it remains unclear how the natural system will adapt. But at the same time, since it has always adapted to changes and has proven more effective at this than humans, this is also where EbA becomes important. $\mathrm{EbA}$ can also play an important role in protecting biodiversity and ecosystem services, the bases on which humans can survive and ensure their sustainability. To do so, EbA is based on a few important principles, such as community participation, inclusion, respect of all traditional and scientific knowledge, accountability, transparency, and trust. As such, EbA promotes ecosystem governance where the bottom-up and top-down approaches to govern merge to ensure positive results. EbA can also be combined with other approaches such as PAR. EbA does not stop with the implementation of strategies or solutions. Monitoring and evaluation are essential components of the process. They allow determination of whether human actions are helping or not helping natural ecosystems to maintain their functions and services. Citizen science can play a role by contributing data and promoting further public engagement and social learning. It demonstrates how the bottom-up approach can help decision making, planning, and management (top-down component) and be more socially acceptable and, in the long term, sustainable.

EbA cannot solve all the climate change impacts in all communities. It is important to understand the conditions very well, which areas are the most vulnerable, and what solutions can be implemented. As mentioned, it is always possible that two approaches are combined to improve the possibility of long-term adaptation. EbA is indeed a long-term process. It is based on the assumption that ecosystems need time to be able to be restored and biodiversity as well as ecosystem services to be re-established. Planners and decision makers at the community level need to acquire enough information and data prior to making any decisions. Through community engagement, they can also gauge the level of social acceptability and in some cases identify other solutions that they may not have thought of, especially solutions based in traditional local knowledge.

In terms of the perspective that community engagement is needed to ensure the sustainability of EbA solutions, it is clear that this would be the ideal situation, and this is often coming in communities that have had some challenges in the past either through disaster or because of the lack of national attention. They, in these cases, take the matter in their own hands. In other cases, it is assumed that either researchers or local authorities increase awareness of the issues and support the community in the process of community 
engagement. In these cases, it is assumed that local authorities embrace the importance of participation to find solutions and are willing to work with various stakeholders. For researchers, it also means that they are willing to accept that not only their knowledge is the right one, but that community members may have traditional local knowledge that can benefit the process of EbA.

There are limitations in these approaches. It may not be possible in all situations to adopt EbA because of physical, ecological, or political constraints. Physical or ecological constraints can be due to the susceptibility of the geology, topology, or other factors that render the need for grey infrastructure. These constraints would be partly understood while doing a vulnerability assessment of the ecosystem. Political climate may also affect the level of involvement of a community. As the number of case studies on EbA increases, it will become possible to add options and possible solutions that can work in different conditions.

Funding: This paper received no external funding.

Institutional Review Board Statement: Some of the work reported in this paper was approved by Brock University's Research Ethics Board \#14-165 and \#18-063.

Informed Consent Statement: Informed consent was obtained from all subjects involved in the study.

Data Availability Statement: This paper does not report any data.

Acknowledgments: I would like to acknowledge several colleagues who either encouraged me to write this paper or who push my reflections further on this challenging topic, including $\mathrm{R}$. Tchoukaleyska, S. Plante, and A. Andrade at the Commission on Ecosystem Management at IUCN.

Conflicts of Interest: The author declares no conflict of interest.

\section{References}

1. Halpern, B.S.; Walbridge, S.; Selkoe, K.A.; Kappel, C.V.; Micheli, F.; D’Agrosa, C.; Bruno, J.F.; Casey, K.S.; Ebert, C.; Fox, H.; et al. A Global Map of Human Impact on Marine Ecosystems. Science 2008, 319, 948-952. [CrossRef]

2. Church, J.A.; Clark, P.U. Sea level change; in climate change 2013: The physical science basis. In Contribution of Working Group I to the Fifth Assessment Report of the Intergovernmental Panel on Climate Change (IPCC); Stocker, T.F., Quin, D., Plattner, G.-K., Tignor, M., Allen, S.K., Boschung, J., Nauils, A., AXia, Y., Bex, V., Midgley, P.M., Eds.; Cambridge University Press: Cambridge, UK; New York, NY, USA, 2013; pp. 1137-1216.

3. Hayhoe, K.; Wuebbles, D.J.; Easterling, D.R.; Fahey, D.W.; Doherty, S.; Kossin, J.P.; Sweet, W.V.; Vose, R.S.; Wehner, M.F. Chapter 2: Our Changing Climate. Impacts, Risks, and Adaptation in the United States: The Fourth National Climate Assessment, Volume II; U.S. Global Change Research Program: Washington, DC, USA, 2018. [CrossRef]

4. Vasseur, L.; Catto, N. Chapter 4-Atlantic Region; Lemmen, D.S., Warren, F.J., Lacroix, J., Bush, E., Eds.; From Impacts to Adaptation: Canada in a Changing Climate 2007; Government of Canada: Ottawa, ON, Canada, 2008; pp. 119-170.

5. Lemmen, D.S.; Warren, F.J.; James, T.S.; Clarke, C.S.L.M. (Eds.) Canada's Marine Coasts in a Changing Climate; Natural Resources Canada: Ottawa, ON, Canada, 2016.

6. Solomon, S. (Ed.) Climate Change 2007: The Physical Science Basis: Contribution of Working Group I to the Fourth Assessment Report of the Intergovernmental Panel on Climate Change; Intergovernmental Panel on Climate Change, Intergovernmental Panel on Climate Change, Cambridge University Press: Cambridge, UK; New York, NY, USA, 2007.

7. Field, C.B.; Barros, V.; Stocker, T.F.; Dahe, Q. (Eds.) Managing the Risks of Extreme Events and Disasters to Advance Climate Change Adaptation: Special Report of the Intergovernmental Panel on Climate Change; Cambridge University Press: Cambridge, UK, 2012. [CrossRef]

8. Bussey, M.; Carter, R.W.; Keys, N.; Carter, J.; Mangoyana, R.; Matthews, J.; Nash, D.; Oliver, J.; Richards, R.; Roiko, A.; et al. Framing Adaptive Capacity through a History-Futures Lens: Lessons from the South East Queensland Climate Adaptation Research Initiative. Futures 2012, 44, 385-397. [CrossRef]

9. Andersson, E. Urban Landscapes and Sustainable Cities. Ecol. Soc. 2006, 11, art34. [CrossRef]

10. Vignola, R.; Locatelli, B.; Martinez, C.; Imbach, P. Ecosystem-Based Adaptation to Climate Change: What Role for Policy-Makers, Society and Scientists? Mitig. Adapt. Strateg. Glob. Chang. 2009, 14, 691-696. [CrossRef]

11. Andrade Pérez, A.; Herrera Fernández, B.; Cazzolla Gatti, R. Building Resilience to Climate Change: Ecosystem-Based Adaptation and Lessons from the Field; IUCN Commission on Ecosystem Management, Ed.; Ecosystem management series; IUCN: Gland, Switzerland, 2010.

12. Hobbie, S.E.; Grimm, N.B. Nature-Based Approaches to Managing Climate Change Impacts in Cities. Philos. Trans. R. Soc. B Biol. Sci. 2020, 375, 20190124. [CrossRef] [PubMed] 
13. Seddon, N.; Turner, B.; Berry, P.; Chausson, A.; Girardin, C.A.J. Grounding Nature-Based Climate Solutions in Sound Biodiversity Science. Nat. Clim. Chang. 2019, 9, 84-87. [CrossRef]

14. Thomsen, D.C.; Smith, T.F.; Keys, N. Adaptation or Manipulation? Unpacking Climate Change Response Strategies. Ecol. Soc. 2012, 17, art20. [CrossRef]

15. Adger, W.N. Vulnerability. Glob. Environ. Chang. 2006, 16, 268-281. [CrossRef]

16. McCarthy, J.J. Climate Change 2001: Impacts, Adaptation, and Vulnerability: Contribution of Working Group II to the Third Assessment Report of the Intergovernmental Panel on Climate Change; Intergovernmental Panel on Climate Change, Ed.; Cambridge University Press: Cambridge, UK; New York, NY, USA, 2001.

17. Petzold, J. Climate change: Impacts, uncertainties and adaptation. In Social Capital, Resilience and Adaptation on Small Islands: Climate Change on the Isles of Scilly; Petzold, J., Ed.; Climate Change Management; Springer International Publishing: Cham, Switzerland, 2017; pp. 9-16. [CrossRef]

18. Fünfgeld, H. Facilitating Local Climate Change Adaptation through Transnational Municipal Networks. Curr. Opin. Environ. Sustain. 2015, 12, 67-73. [CrossRef]

19. Hung, H.-C.; Lu, Y.-T.; Hung, C.-H. The Determinants of Integrating Policy-Based and Community-Based Adaptation into Coastal Hazard Risk Management: A Resilience Approach. J. Risk Res. 2019, 22, 1205-1223. [CrossRef]

20. Ayers, J.; Forsyth, T. Community-Based Adaptation to Climate Change. Environ. Sci. Policy Sustain. Dev. 2009, 51, 22-31. [CrossRef]

21. Forino, G.; von Meding, J.; Brewer, G. Community Based Initiatives to Mainstream Climate Change Adaptation into Disaster Risk Reduction: Evidence from the Hunter Valley (Australia). Local Environ. 2019, 24, 52-67. [CrossRef]

22. Dodman, D.; Mitlin, D. Challenges for community-based adaptation: Discovering the potential for transformation. J. Int. Dev. 2013, 25, 640-659. [CrossRef]

23. Dolšak, N.; Prakash, A. The Politics of Climate Change Adaptation. Annu. Rev. Environ. Resour. 2018, 43, 317-341. [CrossRef]

24. Campos, I.; Vizinho, A.; Coelho, C.; Alves, F.; Truninger, M.; Pereira, C.; Santos, F.D.; Penha Lopes, G. Participation, Scenarios and Pathways in Long-Term Planning for Climate Change Adaptation. Plan. Theory Pract. 2016, 17, 537-556. [CrossRef]

25. Costanza, R.; de Groot, R.; Braat, L.; Kubiszewski, I.; Fioramonti, L.; Sutton, P.; Farber, S.; Grasso, M. Twenty Years of Ecosystem Services: How Far Have We Come and How Far Do We Still Need to Go? Ecosyst. Serv. 2017, 28, 1-16. [CrossRef]

26. Costanza, R.; Limburg, K.; Naeem, S.; O’Neill, R.V.; Paruelo, J.; Raskin, R.G.; Sutton, P. The Value of the World's Ecosystem Services and Natural Capital. Nature 1997, 387, 8. [CrossRef]

27. Corvalán, C.; Hales, S.; McMichael, A.J. Ecosystems and Human Well-Being: Health Synthesis; Millennium Ecosystem Assessment (Program), World Health Organization, Eds.; Millennium Ecosystem Assessment; World Health Organization: Geneva, Switzerland, 2005.

28. Campos, I.S.; Alves, F.M.; Dinis, J.; Truninger, M.; Vizinho, A.; Penha-Lopes, G. Climate Adaptation, Transitions, and Socially Innovative Action-Research Approaches. Ecol. Soc. 2016, 21, art13. [CrossRef]

29. McNiff, J. Action Research: Principles and Practice; Routledge: London, UK, 2013.

30. Woroniecki, S.; Wamsler, C.; Boyd, E. The Promises and Pitfalls of Ecosystem-Based Adaptation to Climate Change as a Vehicle for Social Empowerment. Ecol. Soc. 2019, 24, art4. [CrossRef]

31. Mapfumo, P.; Adjei-Nsiah, S.; Mtambanengwe, F.; Chikowo, R.; Giller, K.E. Participatory Action Research (PAR) as an Entry Point for Supporting Climate Change Adaptation by Smallholder Farmers in Africa. Environ. Dev. 2013, 5, 6-22. [CrossRef]

32. Vasseur, L.; Thornbush, M.J.; Plante, S. Adaptation to Coastal Storms in Atlantic Canada; SpringerBriefs in Geography; Springer International Publishing: Cham, Switzerland, 2018. [CrossRef]

33. Ziervogel, G.; Pasquini, L.; Haiden, S. Nodes and Networks in the Governance of Ecosystem-Based Adaptation: The Case of the Bergrivier Municipality, South Africa. Clim. Chang. 2017, 144, 271-285. [CrossRef]

34. Climate Adaptation Governance in Cities and Regions: Theoretical Fundamentals and Practical Evidence I Wiley. Available online: https: / / www.wiley.com/en-ca/Climate+Adaptation+Governance+in+Cities+and+Regions \%3A+Theoretical+Fundamentals+ and+Practical+Evidence-p-9781118451717 (accessed on 31 January 2021).

35. Crona, B.I.; Parker, J.N. Learning in Support of Governance: Theories, Methods, and a Framework to Assess How Bridging Organizations Contribute to Adaptive Resource Governance. Ecol. Soc. 2012, 17, art32. [CrossRef]

36. Brink, E.; Aalders, T.; Ádám, D.; Feller, R.; Henselek, Y.; Hoffmann, A.; Ibe, K.; Matthey-Doret, A.; Meyer, M.; Negrut, N.L.; et al. Cascades of Green: A Review of Ecosystem-Based Adaptation in Urban Areas. Glob. Environ. Chang. 2016, 36, 111-123. [CrossRef]

37. Reid, H.; Alam, S.S. Ecosystem-Based Approaches to Adaptation: Evidence from Two Sites in Bangladesh. Clim. Dev. 2017, 9, 518-536. [CrossRef]

38. Vasseur, L.; Horning, D.; Thornbush, M.; Cohen-Shacham, E.; Andrade, A.; Barrow, E.; Edwards, S.R.; Wit, P.; Jones, M. Complex Problems and Unchallenged Solutions: Bringing Ecosystem Governance to the Forefront of the UN Sustainable Development Goals. Ambio 2017, 46, 731-742. [CrossRef]

39. Wamsler, C.; Alkan-Olsson, J.; Björn, H.; Falck, H.; Hanson, H.; Oskarsson, T.; Simonsson, E.; Zelmerlow, F. Beyond Participation: When Citizen Engagement Leads to Undesirable Outcomes for Nature-Based Solutions and Climate Change Adaptation. Clim. Chang. 2020, 158, 235-254. [CrossRef]

40. Vasseur, L.; Hart, W. A Basic Theoretical Framework for Community-Based Conservation Management in China and Vietnam. Int. J. Sustain. Dev. World Ecol. 2002, 9, 41-47. [CrossRef] 
41. Wamsler, C.; Schäpke, N.; Fraude, C.; Stasiak, D.; Bruhn, T.; Lawrence, M.; Schroeder, H.; Mundaca, L. Enabling New Mindsets and Transformative Skills for Negotiating and Activating Climate Action: Lessons from UNFCCC Conferences of the Parties. Environ. Sci. Policy 2020, 112, 227-235. [CrossRef] [PubMed]

42. Vasseur, L. Moving from Research into Action on Issues of Climate Change for a Canadian Community: Integration of Sciences into Decision Making. Int. J. Clim. Chang. Impacts Responses 2011, 2, 115-126. [CrossRef]

43. Hall, H.M.; Walsh, J.; Greenwood, R.; Vodden, K. Advancing Innovation in Newfoundland and Labrador: Insights for Knowledge Mobilization and University-Community Engagement. JCES 2016, 9, 13.

44. Groulx, M.; Brisbois, M.C.; Lemieux, C.J.; Winegardner, A.; Fishback, L. A Role for Nature-Based Citizen Science in Promoting Individual and Collective Climate Change Action? A Systematic Review of Learning Outcomes. Sci. Commun. 2017, 39, 45-76. [CrossRef]

45. Paul, J.D.; Buytaert, W.; Allen, S.; Ballesteros-Cánovas, J.A.; Bhusal, J.; Cieslik, K.; Clark, J.; Dugar, S.; Hannah, D.M.; Stoffel, M.; et al. Citizen Science for Hydrological Risk Reduction and Resilience Building: Citizen Science for Hydrological Risk Reduction and Resilience Building. Wiley Interdiscip. Rev. Water 2018, 5, e1262. [CrossRef]

46. Penney, J.; Behan, K.; Pinto, E.; Rodgers, C.; Weigeldt, N. Protecting Your Community from Climate Change. A Training Program for Ontario Municipalities. Clean Air Partnership, Toronto, Canada. 2011, p. 250. Available online: http://www. climateontario.ca/doc/ORAC_Products/CleanAirPartnership/CAP_Municipal_Adaptation_Training_Program.pdf (accessed on 12 December 2020).

47. Blanchard, A.; Vanderlinden, J.P. Pre-Requisites to Interdisciplinary Research for Climate Change: Lessons from a Participatory Action Research Process in Île-de-France. Int. J. Sustain. Dev. 2013, 16, 1. [CrossRef]

48. Bartlett, C.; Marshall, M.; Marshall, A. Two-Eyed Seeing and Other Lessons Learned within a Co-Learning Journey of Bringing Together Indigenous and Mainstream Knowledges and Ways of Knowing. J. Environ. Stud. Sci. 2012, 2, 331-340. [CrossRef]

49. Nalau, J.; Becken, S.; Mackey, B. Ecosystem-Based Adaptation: A Review of the Constraints. Environ. Sci. Policy 2018, 89, 357-364. [CrossRef]

50. Sander-Regier, R.; McLeman, R.; Brklacich, M.; Woodrow, M. Planning for Climate Change in Canadian Rural and Resource-Based Communities. Environments 2009, 37, 35-57. 